\title{
IT Infrastructure Transformation and its Impact on IT Capabilities in the Cloud Computing Context
}

\author{
Rajesri Govindaraju, Rizal Akbar, and Kadarsah Suryadi \\ Faculty of Industrial Technology \\ Bandung Institute of Technology \\ INDONESIA \\ rajesri_g@ti.itb.ac.id, rizal_akbar@gmail.com,kadarsah@ti.itb.ac.id
}

\begin{abstract}
The advent of cloud computing has transformed the way companies managing their information technology (IT) and information systems (IS). Cloud computing provides three different service models, Infrastructure as a Service (IaaS), Platform as a Service (PaaS), and Software as a Service (SaaS). This study was aimed to analyse the effects of IT infrastructure transformation into IaaS model on the changes in IT management capabilities. Based on the literature review, a research framework was developed. The framework suggests four IT capabilities components that can contribute to organizational agility, namely IT supply management, IT-business partnership, IT proactive posture and Change readiness IT capability. The framework was used to guide a case study to collect empirical data in a telecommunication company in Indonesia. Analysing the results of the case study, changes in the organization's IT capabilities as the impact of IaaS adoption were discussed. This study provides insights into efforts to develop the required IT capabilities in order to realise the benefits from cloud computing adoption, in particular the IaaS.
\end{abstract}

Keywords: IT infrastructure, IT capabilities; Cloud computing, IaaS adoption, IT-business partnership, IT supply management, IT-business alignment, Change readiness

\section{Introduction}

Recently many organizations have focused on lowering their operational cost including information technology (IT) and information systems (IS) costs. Information technology is the use of computers, data storage, communication network devices and other physical devices, to create, process, and exchange electronic data. IT includes hardware, virtualization and management or automation tools to be used in an application environment. An information system is an integrated system for recording, storing, sharing, disseminating information to support organizational business processes. An information system consists of processes, computer hardware and software, people and data [1].

To lower their operating cost, many companies have adopted cloud computing. With cloud computing the organizations can cut their costs by reducing infrastructure and administration costs, while having a faster deployment cycles. Cloud computing is defined as the delivery of hardware, systems and the applications over the internet [2]. The delivery of software as within cloud computing is called Software as a Service (SaaS), while the delivery of infrastructure have been referred to as Infrastructure as a Service (IaaS). Cloud computing has provided a powerful IT infrastructure at a modest cost and has helped companies to have more flexibility. With cloud arrangement, large organizations can consolidate their IT infrastructure across distributed locations [3].

Infrastructure of a firm is an important business resource and this resource can provide firms a long-term competitive advantage. IT capability is a firm's ability to acquire, deploy, combine, and reconfigure IT resources to support business strategies and work processes. IT capability is defined as the IT knowledge, IT technical and management skills, and IT practices that can determine how good firms can perform the IT systems implementation, including the IT project management [4]. IT capabilities also include a more strategic IT skills that help to define future 
business needs of a firm. Earlier research suggests that IT capabilities has a positive relationship with organization's performance, corporate enterpreneurship, or competitive advantage [e.g. 5, $6]$.

When companies adopt cloud computing, it is important to analyse the effects of the transformation on the changes needed in the firm's IT capability, in order to benefit from the adoption. Some studies had been done to analyse how the management of IT infrastructure can contribute to firm's performance. Lu and Ramamurthy [7] defined the causal relationship between IT capabilities (include IT infrastructure) and business alignment strategy, and the relationship between business opportunity orientation and the organizational agility. Chen and Tsou [8] develops a model that presents the relationship betwen complementary synergies of IT resources (including people, technology, and organizations) and organizational cabability (including research and development, marketing and operations). Garrison et al. [9] develops a model that links IT capabilities and cloud deployment. The model shows that capabilities that are important for an effective cloud implementation. Further, Prasad et al. [10] suggested an arrangement of IT governance to be used in managing the cloud computing services, in order to increase organizational performance. Garrison et al. [11] did a study on the success factors in deploying cloud computing. Prasad and Green [12] did a study on the adoption of cloud computing service (CCS) and the impact on the risk profile of an organization. Fink [13] in a research on resource-based and process-based IT capabilities stated that structural mechanisms are an important factor determining the value of different IT capabilities.

To conclude, there are a few studies that have addressed issues related to IT capabilities and IT governance as the impact of changes in the IT infrastructure management such as Garrison et al. [9], Fink [13] and Prasad and Green [12]. Though some authors mentioned that cloud computing can increase the organization's competitive advantage through increased IT agility and business agility [e.g. 14], there is a lack of studies that explores the IT capabillity components needed by organizations adopting Iaas in order to effectively facilitate the achievement of business agility. The aim of this study is to explore the IT capabillities needed by an organization that adopt IaaS. The capability is expected to support the organization in gaining better performance. The remaining part of the paper is structured as follows. Firstly an overview of literature on IT infrastructure, IT capability and cloud computing is presented in the next section. Following this, conceptual framework development is described. Then the research design is presented, followed by discussions on the results. The final sections note the overall analysis from the study results and directions for future studies.

\section{Literature Study}

\section{A. IT Infrastructure}

IT infrastructures are formed of several kinds of components that can be either individual hardware entities (in the case of servers, storage systems, printers, hubs, switches, routers, and others) or Infrastructure Groups that are composed of infrastructure components (as in the case of a cluster of servers). Therefore, IT Infrastructure Components are divided into Physical Hardware, Virtual Hardware, and Infrastructure Groups [5]. IT infrastructure is an arrangement of technical components and IT services that comprises of network devices, data storage, platform and IT applications [15]. IT infrastructure includes not only physical components, but also the quality and frequency of maintenance of all the components [4]. IT infrastructure the most important basis for a shared IT services to be used by multiple IT systems.

Recently, investment in IT infrastructure is usually done to provide a flexible base for future business initiatives. Flexibility provides by the IT infrastructure is meant facililate firms in anticipating the future business [16]. IT infrastructure of a firm will determine a firm's competitive position. The investment in IT infrastructure can help firms to improve their crossfunctional organizational processes, to do cycle time improvement and to create new innovative product and services. Thus in general, IT infrastructure can help firms to creates value and improve their performance. 
Flexible IT infrastructure supports the firms to share information across business functions within the firm and also across firms. With the existence of standard software packages and open architectures, IT infrastructure can not always be used to support firm's innovation, because the infrastructure may not always be imitated. Therefore, it is important to analyse the extent to which the flexibility of a firm's IT infrastructure could directly or indirectly contribute to the competitive advantage of the firm [17].

\section{B. IT Capabilities}

IT capabilities is the ability of an organization to mobilize and organize IT [18]. IT capabilities include technical IT skills, managerial IT skills, and IT relationships capability [19, $5,17,6,13]$. Chen et al. [20] provides explanation of how IT capabilities can help to support the effectiveness of corporate enterpreneurships. Firstly, IT capabilities provides the support by providing information required by relevant activities and providing an enabling environment within a company. Secondly, IT capability can support communication and interaction within and across business integration [20].

Ravichandran and Lertwongsatien [21] defines IT capabilities as a concept that comprises of three constructs: IT infrastructure flexibility, IT human capital, and IT partnership quality. While IT Infrastructure is composed of IT tangible assets, IT human capital comprehend the related technical and managerial abilities. Park et al. [22] defined IT human capital as IT human capabilities which is the ability in managing resources related to IT that consists of four dimensions: Technology management abilities, business process management abilities, interpersonal and managerial abilities, and technical abilities. Bharadwaj [5] argued that the capabilities are developed over time through experience and therefor these capabilities are specific to the organization, difficult to acquire and complex to imitate.

Lu and Ramamurthy [7] did a study that modelled a relationship between IT capability and organizational agility. The model developed is presented in Figure 1. IT capability is divided into three constructs: 1) IT infrastructure capability, 2) IT business spanning capacity and 3) IT proactive stance. To address IT partnership quality, Kim et al. [23] use the term IT management capabilities which encompass knowledge assets, client orientation, synergy and abilities in aligning IT and business. Studies that consider IT partnership quality or IT management capabilities emphasize the importance of IT strategy and business alignment [21, 22, 23].

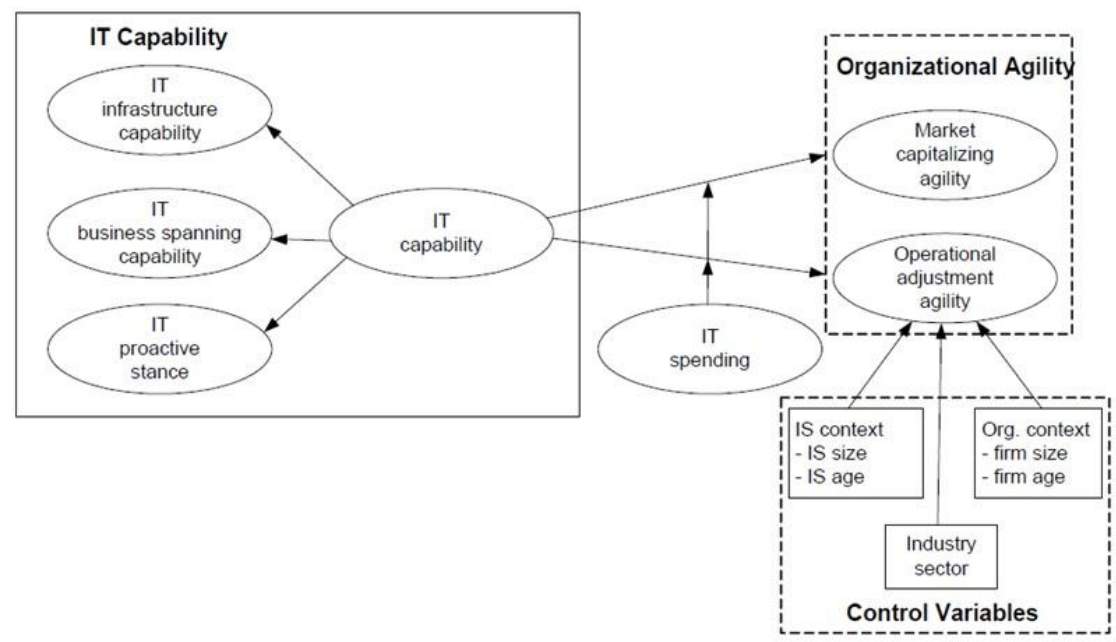

Figure 1. The relationship between IT capability and organizational agility [7]

\section{Cloud Computing}

Cloud computing is the delivery of hardware, systems and the software applications over the internet [2]. Cloud computing implementation radically change the way IT services are 
designed, developed, maintained and financed [24]. Computing environment changes radically. On the one hand, computing is not anymore so expensive and can be seen as a commodity. On the other hand, for some organizations, the increasing complexity of managing the whole infrastructure has made computing more expensive than before [24].

According to many authors such Wang et al. [25] cloud computing services can be divided into three different models: Infrastructure as a Service (IaaS), Software as a Service (SaaS) and Platform as a Service (PaaS). With IaaS, vendors supply customers with infrastructures needed to support their business operations, including the hardware, servers, operating systems, data storages, and networking equipment in an on-demand service [25]. This way cloud computing provides a powerful IT infrastructure at a lower cost. In addition, individuals and companies can get benefits from no worries regarding technology obsolescence and lack of flexibility. For big companies IaaS can provide supports to consolidate their IT infrastructure across distributed locations [3].

PaaS is a cloud-based service where vendors provide companies with the computing platform that allows the company to create software applications without the complexity of having to purchase and maintain the necessary IT infrastructure. Through a web browser, users can customize, deploy and test their applications [25]. With SaaS, the users pay the services based on the use of the application(s). The usage of the application can be a service on demand or service got through a subscription. The cloud computing vendor is responsible for all the necessary changes in the application [25]. This way, companies can focus on their core business activities.

Armbrust et al. [2] divided cloud computing into two types. The first is the one providing applications which have long been referred to as SaaS. The second is the one providing infrastructure, which is called IaaS. While some definitions differentiate IaaS and PaaS, Armbrust et al. [2] merged the two into IaaS because they argued that the line between "lowlevel" infrastructure and a higher-level "platform" is not clear. They believe that "the two are more alike than different" [2, p. 51]. With SaaS, cloud computing vendors offer business applications directly to individual users users. With IaaS, cloud computing vendors offer computing and storage capability, such as the servers, operating system, data storage and networking infrastructure.

\section{Research Framework Development}

Firms adopt the cloud computing to enable full business transformation, thus adopting IaaS means that the firms transforming their ways of operating. To realise as much as possible potential benefits from cloud computing, some necessary changes in the operating environment are required. In a cloud computing environment, an organization's competitive advantage can be achieved by acquiring the ability to plan and implement cloud-based services, using a strategic and holistic view [9].

Cloud computing can increase the organization's competitive advantage through increased IT agility and business agility. By increasing the speed of deployment, through cloud computing organizations can improve their agility and increase their competitive advantage [26]. Most of the research mentioned agility as one of the main attributes of cloud computing [14]. Agility can be described as the capability to effectively sense and respond to environmental changes. To realise business value from IaaS adoption organizations need to acquire a number of IT capability components which when linked with the IT infrastructure flexibility provided by cloud computing, will increase the agility of the company as a whole.

In this study, a conceptual framework is developed to describe the IT capability concept that is related to IT agility driven by cloud computing. Based on synthesis of previous works, the framework developed in this study is presented in Figure 2. In this framework, IT capability is positioned as the enabler of organizational agility which comprises of IT-IT-business alignment and IT-driven business innovation.

IT-business alignment is a dynamic state in which IT can be used by business organization to achieve business objectives such as improved financial performance or market 
competitiveness. Some authors defined IT-business alignment as the ability of IT to produce business value, which is more focused on the outcome rather than means. IT-business alignment includes business transformation, in which organizations redesign business processes in order to realize efficiencies or proposing new business processes made possible by new IT. Without a proper alignment, many organizations develop IT systems and do not get adequate benefit because IT and business do not share the same understanding, objectives, and culture. IT-driven business innovation refers to major business innovation which is driven by IT. In this case, information technology is used as an instrument to transform parts of the business in a rather radical and innovative way. This includes exploring other revenue streams and integrating other facets of their business into each other.

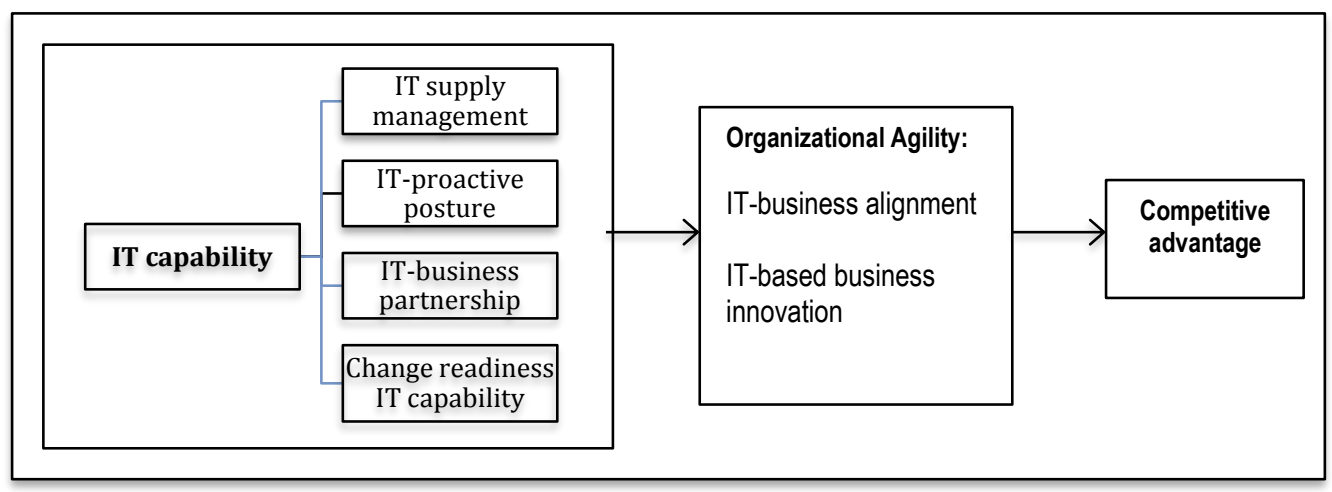

Figure 2. Conceptual Framework

IT capability consists of four dimensions, namely: IT supply management, IT-business partnership, IT proactive posture and Change readiness IT capability. Firstly IT supply management is an important part of IT capability aiming at assuring that the company's IT infrastructure can effectively support the business needs. Secondly, IT-business partnership is meant to address the close collaboration between IT and business which enables its business processes to be responsive and flexible. Thirdly the Proactive IT posture addresses the ability to respond quickly to the market needs by anticipating and sensing relevant changes in IT and the opportunities created by the technologies [27]. Finally, considering that implementing the alignment of IT and business includes not only a technical component, but also an organizational change management component, Change readiness IT capability is proposed as the last component of IT capability.

Cloud computing converts traditional IT maintenance and usage into simpler IT services. Service quality is critical to firm-level level IS success. Among others, cloud service quality include security, availability and scalability [26]. In this study IT supply management refers to the management of IT services provided by cloud vendors including the stability of supply, security, integrity, and the cost associated with the service provided.

To establish organizational agility there is a need to develop trust and strong collaborations between the IT and business groups. Partnership and synergy between IT and business managers may leads to better joint decision making, more suitable and effective strategic applications, and better systems implementation [27]. The synergy between IT and business activities also facilitates fast and efficient innovation process that often require radical changes and reengineering of organizational processes and information systems. IT business partnership can facilitate informal and agile decision making that is very often needed in turbulent environments [28]. Further, to trigger IT-driven business innovations, firms should anticipate and sense relevant opportunities created by emerging technologies [7]. IT proactive posture involves firm's ability to sense major IT innovations, consider the potential for the firm and, then identify, select, and pursue IT innovations [7]. 
Change readiness IT capability is the ability of companies to rapidly develop and implement information systems within short development cycle times for long-term competitive advantage [29]. This capability involves combining IT groups' business expertise and IT skills within the organization. Besides, change readiness also involves managing the necessary communication and expectation among different stakeholder groups. Change agents have to be enabled and oriented to align all stakeholders towards the program vision. Governance structures could help in facilitating the communication and effective decision making.

\section{Research Methodology}

This study is exploratory in nature, aiming to provide a qualitative overview of the impact of IaaS adoption on the organizational's IT capability, taking into account the company needs to increase its agility. Data collection was done at a telecommunication company in Indonesia that has adopted IaaS. Data gathering was undertaken through observations, semi-structured interviews and document analysis [30,31]. The data collected as a whole explain retrospective and current situations related to IaaS adoption and the impact on organizational capability in the case company. The data collection took place between May 2016 and August 2016. A number of in-depth interviews were carried out to collect data from the company's executives. Interviewees for this research are vice director for IT and IT executives responsible for IT management and planning. These are the most important executives in charge of the management of IT aupply and services to business departments in the organization. An interview protocol was developed based on the literature. This protocol consists of a list of questions which was used to guide the interview process.

Each interview was started with questions regarding the interviewee's role in IT/IS management of the company. Then, they were asked to describe their background, and later the interviewees were asked about specific experiences and understanding regarding the impact of cloud computing adoption on IT capability components, considering the company needs to become more responsive to the changes in the market and external business environment.

Results

Data was collected from a telecommunication company in Indonesia called TelCo. Telco's motivation for cloud computing adoption is to replace the company's old infrastructure operation which mostly relies on manual processes, and to maintain and support a growing number of systems and applications. The old condition had resulted in difficulties in meeting business response expectations and time to market objectives, lack of IT agility to respond to new services launched, and low level of service. Interview with vice director of IT concluded that with cloud adoption TelCo realize cost reductions through the consolidation and virtualization of current systems, to eliminate duplication of resources, operations, and infrastructure. Currently TelCo deliver Telecommunication, Information, Media \& Edutainment, and Services (TIMES) to its broad customers in Indonesia and several areas abroad. The IT Infrastructure consolidation stages in TelCo Indonesia is presented in Figure 3.

The transformation of IT infrastructure from distributed conventional arrangement to centralized arrangement and later to cloud computing platform arrangement has brings benefits for the companies both regarding the capacity and ease of administrative management. The transformation has also significantly reduced the number of personnels required to run the billing and finance process. The reduction of 880 to 160 personnels shows that the consolidation of data centers from 27 sites to 4 sites has brought positive impact on the personnels efficiency. The consolidation of data centers has also driven the organization transformation from distributed billing and finance process arrangement involving 7 regions to the centralized arrangement of billing and finance process.

The capacity of processing power and storage in cloud computing platform doubled while the total cost of ownership of the new infrastructure fell half of the total cost of ownership of conventional configuration. The contract management of the IT infrastructure operation and maintenance was also significantly reduced from 56 contracts to 15 vendors to become single 
contract to a cloud computing operation and maintenance vendor, which in this case is a subsidiary of TelCo Indonesia specialized in delivering IT services.

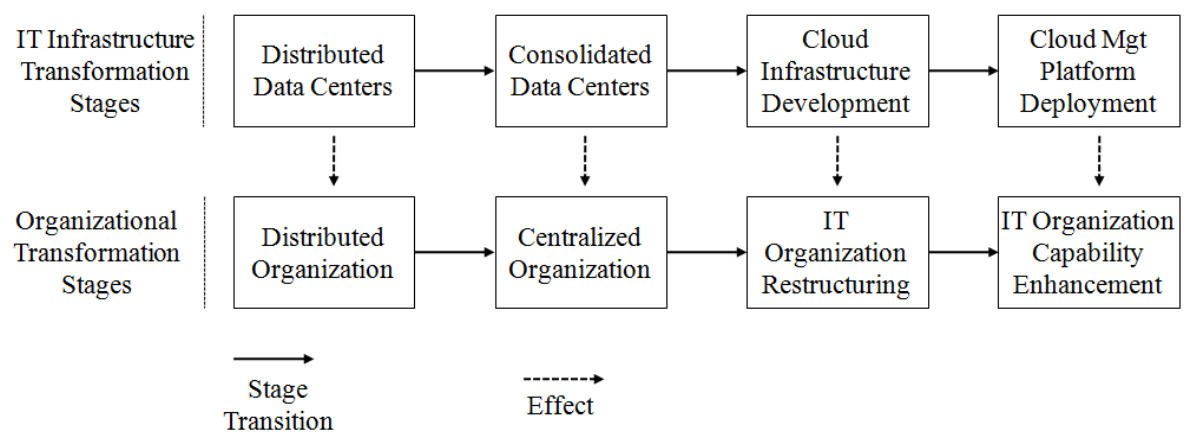

Figure 3. IT Transformation Stages in the Case Company

In the next part, based on the results of data collection and analysis, discussions regarding each component of IT capabilies are presented.

IT supply management. The use of the virtualised infrastructure provides the capability to deploy infrastructure as required. Thus, IT supply management at TelCo focuses on how the virtualised infrastructure can be managed properly to meet customer and business requirements. Server deployments was templated as far as possible, resulting in a significant reduction in design planning and implementation effort, cost and time. Since most of the physical work involved in infrastructure deployment is bypassed, server implementation does no longer require coordination amongst multiple parties. To manage the services supplied by cloud computing vendor, chief information officer (CIO) in this company takes an important role in proactively managing the cloud resources, and leading in establishing and enforcing cloud service level agreements. Contract facilitation and monitoring were also considered important by the interviewees. Further, CIO always monitors the new opportunities of the cloud computing services. Relationships with vendors were developed through better communication and socialization and this had led to a higher level of trust between TelCo and their vendors. Vendor negotiation capability and a clear vision of the intended business goal is very essential for effective supply management in a cloud-enabled IT organization.

One interviewee stated, "we need to make a clear contract to address some important requirements. For example, we can state in the contract where our data is to be stored and because our company is big, very often we can ask their agreement that they use dedicated servers us. This is more benefecial from a security and privacy point of view". The importance of a formal control mechanism that is agreed by both parties and the critical role in managing the SLA were also highlighted during the interview. Interviewees also mentioned that it is not easy to manage their cloud providers. One of the interviewees stated, "Managing IT resources through a provider requires a different set of skills."

IT-business partnership. In order to facilitate effective IT deployment, it is essential for business analysts and IT analysts to gain a shared understanding of the impact of IT systems on business processes. Interviews suggest strongly that business analysts and IT analysts need to match both the business requirements and the technical options. Further, one interviewee stated that IT organizational structure, how assignment of IT staffs in business units are arranged, perhaps need realignment. This close colaboration and partnership is vital and should be develop to speed up follow up process when there are new ideas for business innovation. One interview mentioned that partnership is one of the keys to develop systemic relationships between company's enterprise architecture and the current and future business activities of the company. IT-business partnership in the case organization has led to a more intensive sharing and exchange of knowledge between IT and business managers. 
Proactive IT posture. Cloud computing deployment has enabled TelCo to provide its customers with a larger scale of IT services, including infrastructure support and collaborative platforms, with assured data integrity and security, and simple management of the environment. Thus, cloud has provided TelCo with a strong technical infrastructure that can support business model innovation. In this case, IT capabilities to trigger IT-driven business innovation innitiatives was considered very important. As an example, with the availability of flexible infrastructure support, TelCo has been quickly preparing TIME package/product bundling of the TelCo Group.

Change readiness IT capability. Some interviewees emphasized that to benefit more from infrastructure flexibility, organizations need to have the capability in managing changes in the landscape of technology which in turn will facilitate easier alignment between IT and the company strategy. This capability is very important because of the short software product life cycle and the fast development in devices and associated platforms. One interviewee stated, "IT department need to improve "the ways of working in order to be faster in reacting to change and pursue the opportunity". Interview with vice director of IT mention that to meet the target of the company regarding the operational agility, Telco has standardized change management process and change models. TelCo introduces a governance structure, IT policy and operational management frameworks that support the organization in aligning the application development, test, release, provisioning, security, and daily operational management activities. A set of metrics, role-based dashboards, and workflow engine are used to support the implementation of the framework. The intention is to improve project deployment agility that can lead to Increased product diversity and higher revenue.

\section{Discussions}

Cloud computing adoption has brought a huge value to TelCo as a firm. First of all, using cloud computing technology, TelCo is getting more flexible and scalable, and this has increased TelCo's speed in developing and launching new products at a lower cost of management. Other impacts that had been realised include flexibility in setting the solutions to meet the business needs. The shorter time-to-market for a new service helps TelCo to maintain and even increase the market. The transformation towards cloud arrangement at Telco had also driven the development of IT organization and personnel capability. This result is consistent with the theory proposed by Aral and Weill [16] which mentions that IT assets, in this case is IT infrastructure, drive the organization to build IT skills and IT management quality. In this study it was shown that with a flexible IT infrastructure, the IT organization needs to have the ability to sense and respond to opportunities in the market with IT-driven business innovation and this ability has to be accompanied by the ability to implement change quickly and effectively. This result is also in line with the framework of IT business value proposed by Wiengarten et al. [32] which highlights the importance to adapt the human IT resources and organizational arrangements as an impact of changes in technological IT resources if organizations are expecting a positive impact on firm performance.

The results of the empirical study highlight the importance of formal controls through contracting that has also been discussed in the outsourcing literature such as Kern and Willcocks to be an important issue in managing the IT supply [33]. The results regarding IT-business partnership also emphasize the importance of IT strategy and business alignment which is in line with Ravichandran and Lertwongsatien [21] and Park et al. [22]. The study results confirm that IT-business partnership has led to a more intensive knowledge sharing and exchange between business and IT managers which is in line with Ross et al. [34]. This finding highlights the critical importance of bridging the gap between IT and business in the organizations. Structural alignment that is aimed fill the gap in the organization can help companies to increase benefits realisation from cloud-enabled IT flexibility improvement.

The findings of the study also support the proposition that cloud computing can support business model innovation in the company by first improving the proactive IT posture. This proactive posture will have a higher impact on organizational agility when proper leadership and 
architecture planning are in place because the realisation of the business innovation and business alignment are strongly influenced by top management decision-making. Systems thinking as a part of IT capability is very important because it supports company's decision process, especially decisions with longer time horizons. The importance of systems thinking related capability is already highlighted by Willcocks and Feeny [35].

This study also found an empirical support to stress the importance of change management capability to support organizational's IT-enabled agility. This capability is considered critical considering the short life cycle of IT and software related products. For this, it is necessary for organizations to institutionalize a standardized change management process and policies. These governance structures will improve project deployment agility that can support company's innovation. The company's innovation performance is one of the most important part of company's competitive advantage [32].

\section{Conclusion}

Transformation of IT infrastructure in TelCo has led to improvement in a number of business performance indicators due to the increase in capacity and flexibility of IT infrastructure. However, to fully realize the benefits offered by IaaS, on the one hand, IT organization has to manage the demand from the business side, the supply from the vendor side, the users' priorities, and keep up with the changing technologies. Besides, IT unit has also the role in proposing ideas for IT-driven innovation and managing the change in the organization and delivering the systems and applications required to support the operations of the business. To support these requirements, companies needs to strengthen the IT-business partnerships. This study had shown that IaaS adoption has changed the nature of relationship between the business departments and the IT organization. The ability to manage this complex environment is vital in realising the potentials offered by cloud computing.

The study has highlighted the effects of IT capabilities on firm's innovation in a cloud computing setting. However a more comprehensive study based on intensive survey is required to examine the way cloud arrangement can facilitate the IT-enabled innovation at a firm level. Therefore, future study can examine how IT capabilities can have an impact on product innovation using a quantitative statistical approach. Besides, studies can be done further to develop a cloud-based change analysis framework and an adapted IT capability maturity model for cloud adopting companies.

\section{Acknowledgement}

This work is partly supported by Ministry of Research, Technology and Higher Education of the Republic of Indonesia. The authors gratefully acknowledge the support.

\section{References}

[1]. R. Hirscheeim, H. Klein and K. Lyytinen, "Information Systems Development and Data Modeling, Conceptual and Philosophical Foundations". Cambridge University Press, Cambridge, 1995.

[2]. M. Armbrust, A. Fox, R. Griffith, A. D. Joseph, R. Katz, A. Konwinski, G. Lee, D. Patterson, A. Rabkin and I. Stoica, "A View of Cloud Computing," Communications of the ACM, vol. 53, pp. 50-58, 2010.

[3]. S. Greengard, "Cloud Computing and Developing Nations," Communications of the ACM, vol. 53, no. 5, pp. 18-20, 2010.

[4]. Chakravarty, R. Grewal and V. Sambamurthy, "Information Technology Competencies, Organizational Agility, and Firm Performance: Enabling and Facilitating Roles," Information Systems Research, vol. 24, pp. 976 - 997, 2013.

[5]. J. vom Brocke, S. Debortoli, O. Müller and N. Reuter, "How in-memory technology can create business value: insights from the Hilti case". Communications of the Association for Information Systems, vol. 34, no. 1, pp. 151-167, 2014. 
[6]. M. Zhang, S. Sarker and S. Sarker, "Unpacking the Effect of IT Capability on the Performance of Export-focused SMEs: A Report from China," Information Systems Journal, vol. 18, no. 4, pp. 357-380, 2008.

[7]. Y. Lu and K. Ramamurthy, "Understanding the Link Between Information Technology Capability and Organizational Agility: An Empirical Examination," MIS Quarterly, vol. 35, no. 4, pp.931-954, 2011.

[8]. J. S. Chen and H. T. Tsou, "Performance Effects of IT Capability, Service Process Innovation, and the Mediating Role of Customer Service," Journal of Engineering and Technology Management, vol. 29, no. 1, pp. 71-94, 2012.

[9]. G. Garrison, S. Kim and R. L. Wakefield, "Success Factors for Deploying Cloud Computing," Communications of the ACM, vol. 55, no. 9, pp. 62-68, Sept. 2012.

[10]. A. Prasad, P. Green, and J. Heales, "On governance structures for the cloud computing services and assessing their effectiveness," International Journal of Accounting Information Systems, vol. 15, no. 4, pp. 335-356, 2014.

[11]. G. Garrison, S. Kim, R. L. Wakefield, "Success Factors for Deploying Cloud Computing," Communications of the ACM, vol. 55, no. 9, pp. 62-68, 2012 (Sept).

[12]. A. Prasad and P. Green, "Governing Cloud Computing Services: Reconsideration of IT Governance Structures," International Journal of Accounting Information Systems, vol. 19, pp. 45-58, 2015.

[13]. L. Fink, "How Do IT Capabilities Create Strategic Value\&Quest: Toward Greater Integration of Insights from Reductionistic and Holistic Approaches," European Journal of Information Systems, vol. 20, no. 1, pp. 16-33, 2011.

[14]. M. Carroll, A. van der Merwe and P. Kotze, "Secure Cloud Computing: Benefits, Risks and Controls", Information Security South Africa (ISSA), pp. 1-9, 2011.

[15]. N. Roberts and Grover, "Leveraging Information Technology Infrastructure to Facilitate a Firm's Customer Agility and Competitive Activity: An Empirical Investigation," Journal of Management Information Systems, vol. 28, pp. 231-269, 2012.

[16]. S. Aral and P. Weill, "IT Assets, Organizational Capabilities, and Firm Performance: How Resource Allocations and Organizational Differences Explain Performance Variation," Organizational Science, vol. 18, no. 5, pp. 763-780, 2007.

[17]. G. D. Bhatt and G. Grover, "Types of Information Technology Capabilities and Their Role in Competitive Advantage an Empirical Study," Journal of Management Information Systems, vol. 22, pp. 253-277, 2005.

[18]. Z. Wu, Z. Huang and B Wu, "IT capabilities and firm performance: an empirical research from the perspective of organizational decision-making" In Proceedings of the 2008 IEEE ICMIT, pp. 526-531, Bangkok, 2008.

[19]. F. J. Mata, W. L. Fuerst and J. B. Barney, "Information Technology and Sustaining Competitive Advantage: A Resource-based Analysis," MIS Quarterly, vol. 19, no. 4, pp. 487-505, 1995.

[20]. Y. Chen, Y. Wang, S. Nevo, J. Benitez-Amadoand G. Kou, "IT capabilities and product innovation performance: The roles of corporate entrepreneurship and competitive intensity". Information \& Management, vol. 52, no. 6, pp. 643-657, 2015.

[21]. T. Ravichandran and C. Lertwongsatien, "Effect of Information System Resources and Capabilites onf Firm Performance: A Resource-Based Perspective," Journal of Management Information Systems, vol. 21, pp. 237-276, 2005.

[22]. J. Y. Park, K. S. Im and J. S. Kim, "The Role of IT Human Capability in the Knowledge Transfer Process in IT Outsourcing Context," Information \& Management, vol. 48, no. 1, pp. 53-61, 2011.

[23]. G. Kim, B. Shin, K. K. Kim and H. G. Lee, "IT Capabilities, Process-Oriented Dynamic Capabilities, and Firm Financial Performance," Journal of the Association for Information Systems, vol. 12, no. 7, pp. 487-517, 2011.

[24]. S. Marston, Z. Li, S. Bandyophadhyay, J. Zhang and A. Ghalsasi, A., "Cloud Computing: The Business Perspective", Decision Support System, vol. 51, pp. 176-189, 2011. 
[25]. Q. Wang, K. Wang, K. Ren and W. Lou, "Towards Secure and Dependable Storage Services in Cloud Computing," IEEE Transactions on Services Computing, vol. 5, no. 2, pp. 220-232, 2011.

[26]. Benlian and T. Hess, "Opportunities and Risks of Software-as-a-Service: Findings from a Survey of IT Executives," Decision Support Systems, vol. 52, no. 1, pp. 232-246, 2011.

[27]. P. Weill and J. Ross, IT Governance: How Top Performers Manage IT Decision Rights for Superior Results, Harvard Business School Press, Boston, 2004.

[28]. S.L. Brown, and K. Eisenhardt, "The Art of Continuous Change: Linking Complexity Theory and Time-Paced Evolution in Relentlessly Shifting Organizations," Administrative Science Quarterly, vol. 42, pp. 1-34, 1997.

[29]. E. Clark, N. C. Cavanaugh, C. V. Brown and V. Sambamurthy "Building Change Readiness Capabilities in the IS Organization: Insights from the Bell Atlantic Experience," MIS Quarterly, vol. 21, no. 4, pp. 425-455, 1997.

[30]. R. K. Yin, Case Study Research Design and Method: Applied Social Research Methods Series, $2^{\text {nd }}$ ed, Sage Publications, Newbury Park, CA, 1994.

[31]. J. W. Creswell, Research Design: Qualitative, Quantitative, And Mixed Methods Approaches, $2^{\text {nd }}$ ed., Thousand Oaks, CA: Sage, 2003.

[32]. F. Wiengarten, P. Humphreys, G. Cao and M. McHugh, "Exploring the Important Role of Organizational Factors in IT Business Value: Taking a Contingency Perspective on the Resource-Based View," International Journal of Management Reviews, pp. 1-17, 2012.

[33]. T. Kern and L. P. Willcocks, "Exploring Relationship in Information Technology Outsourcing: The Interaction Approach," European Journal of Information Systems, vol. 11, no. 1, pp. 3-19, 2002.

[34]. J. W. Ross, C. M. Beath and G.. L. Goodhue, "Develop Long-term Competitiveness Through IT Assets," Sloan Management Review, vol. 38, no. 1, (38:1), pp. 31-42, 1996.

[35]. L.P. Willcocks and D. Feeny, "IT Outsourcing and core is capabilities: Challenges and lessons at DuPont”, Information systems management, vol. 23, no. 1, pp.49-56, 2006.
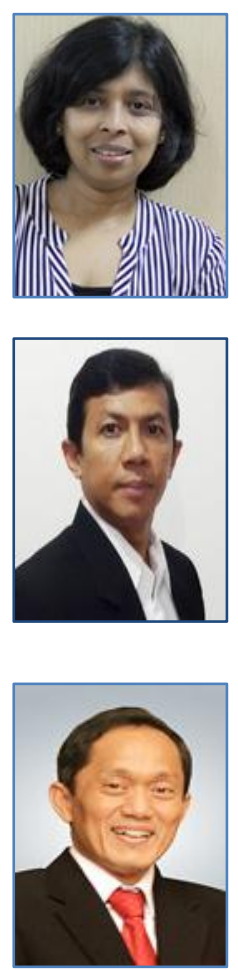

Rajesri Govindaraju is an Associate Professor in the Faculty of Industrial Technology, Bandung Institute of Technology, Indonesia. She finished his bachelor from Informatics Department, ITB, in 1993. She received a Doctoral Degree from University of Twente, Netherlands in 2002. She has been involved in multiple disciplinary research in the areas of Planning and Implementation of Information System, ERP, e-Business, and knowledge Management Systems.

Rizal Akbar, Currently VP IT Strategy and Governance, Telkom Indonesia. He has 22+ years working experience in the area of IT Strategy, IT Policy, IT Service Management, IT Investment, IT Architecture, IT System Development, IT Portfolio Management, and IT Governance. He was certified in CISA (Certified Information System Auditor) and CGEIT (Certified in the Governance of Enterprise IT). His current research in Bandung Institute of Technology focusing in the IT contribution to firm performance.

Kadarsah Suryadi is a Professor in the Faculty of Industrial Technology, Bandung Institute of Technology, Indonesia. He received a Doctoral Degree from the University of Aix Marseille-3, France in 1992. He has been involved in multiple disciplinary research in the areas related to Decision Support System and Knowledge Management. 